\title{
Analytical Model for Travel Time-Based BPR Function with Demand Fluctuation and Capacity Degradation
}

\author{
Junjie Zhang, ${ }^{1,2}$ Miaomiao Liu, ${ }^{3}$ and Bin Zhou (iD ${ }^{1}$ \\ ${ }^{1}$ School of Electronic and Information Engineering, Beihang University, No. 37 Xue Yuan Lu, Hai Dian Zone, Beijing, China \\ ${ }^{2}$ Hefei Innovation Research Institute, Beihang University, No. A1 Intelligent Industrial Park of New Station High-Tech \\ Industrial Development Zone, Hefei, Anhui, China \\ ${ }^{3}$ Beijing Key Laboratory for Cooperative Vehicle Infrastructure Systems and Safety Control, \\ School of Transportation Science and Engineering, Beihang University, No. 37 Xue Yuan Lu, Hai Dian Zone, Beijing, China
}

Correspondence should be addressed to Bin Zhou; binzhou@buaa.edu.cn

Received 17 May 2019; Revised 20 September 2019; Accepted 9 October 2019; Published 3 November 2019

Academic Editor: Alexander Paz

Copyright (c) 2019 Junjie Zhang et al. This is an open access article distributed under the Creative Commons Attribution License, which permits unrestricted use, distribution, and reproduction in any medium, provided the original work is properly cited.

This study presents a stochastic model based on the link performance function of the Bureau of Public Roads to assess the reliability of travel time in the transportation network. Empirical studies have verified that the variability of travel time can be ascribed to demand fluctuation and the degradation of the capacity of the stochastic network. The mean-variance approach in previous research presented the budget model of travel time, with the capacity of the stochastic network and elastic demand as the sources of uncertainty of travel time. Previous research was devoted to the study of estimation of travel time considering a single factor or a factor independent of these two sources. Meanwhile, this study introduces the current degeneration coefficient of capacity (CDC) and the density distribution function of road section saturation (DDFS) with simultaneous network capacity and traffic demand. Sensitivity analysis method for the parameters of the proposed model is investigated theoretically using the sensitivity model of traffic capacity degradation. Results of case analysis show that the DDFS and CDC have an effect on the decision of travelers regarding the choice of route. The empirical analysis also illustrates the effectiveness of the computational approach and the proposed model.

\section{Introduction}

The reliability of the transportation system has been gaining considerable attention because of the increase in traffic demand and serious congestion. Many scholars have investigated the three aspects of traffic reliability, which includes connectivity [1-3], capacity $[4,5]$, and travel time [6-11]. Among these aspects, travel time reliability has been identified as an important indicator of the performance of the transportation network [12-14]. Travel time reliability is an important performance measure for assessing traffic conditions and the extent of congestion on a roadway. Travelers are usually concerned with the appropriate time of departure from their point of origin and the reliability of arriving on time at their destination, which are related to travel time reliability. Analysis and evaluation of travel time reliability will benefit the organization of traffic flow and traveling service.

Travel time is an operational measure of network flow related to the interaction between traffic demand and supply. Traffic demand and supply can be characterized by traffic flow and link capacity in the road network. Therefore, performances of road networks, such as stochastic capacity and saturation of road sections, have an evident effect on travel time and its reliability. Stochastic capacity and saturation of road sections are related commonly to the uncertainty of demand and supply. The key influencing factors of supply uncertainty that have a serious effect on link capacity include natural disasters, routine road maintenance, random accidents, special events, and bad weather. Meanwhile, demand uncertainty indicates the random change of traffic demand related to origin to destination $(\mathrm{OD})[4,15]$. 
Several scholars have conducted related research on travel time reliability that considers the demand or capacity. Bell and Lida [3] analyzed travel time reliability under the daily traffic demand shift. Shao et al. [16] derived travel time reliability based on the assumption that the OD demands are distributed normally. Zhou and Chen [17] presented a link flow distribution that follows the log-normal distribution to estimate travel time. Clark and Watling [7] proposed a computational procedure to construct the probability density function of link travel times under conditions of stochastic demand. Asakura [18] considered travel time reliability under the low link capacity because of damaged roads. Lo et al. [19] developed an approach to relate the variability of travel time caused by variations in the link capacity of the stochastic network with the aversive behavior of travelers regarding the risk in choosing a route. These studies only discussed one of the two key factors for travel time variability. A change in only one factor, such as traffic demand or supply, is adopted in the estimation of travel time because it has a certain effect on the estimation results.

Recently, some studies have considered demand fluctuation and the effects of the degradation of link capacity on travel time variability to decide on a traveler's choice of route [20-22]. Chen et al. [4] treated the OD demands and link capacity as continuous random variables and used the Monte Carlo simulation technique to calculate travel time reliability. Lam et al. [20] considered the link capacity to be a nonincreasing function of rainfall intensity, and the travel demand is stochastic. Siu and Lo [22] assumed that the randomness of travel demand originates from the change in the volume of noncommuters, and the link capacity is subject to stochastic degradation. Although the current research considered the fluctuation of travel demand and degradation of link capacity, the scholars merely assumed that travel demand is treated as a continuous random variable, or the link capacity followed some distribution. Few scholars treated the fluctuation of travel demand and degradation of link capacity as an entire random variable to analyze the travel time reliability. Based on the relationship among travel time, traffic supply, and demand, which is described mainly through several conventional road impedance functions, such as the link performance function of the Bureau of Public Roads (BPR) [23], Davidson's road impedance function [24], and the linear function and the regression road impedance model used by Germany and Japan, respectively, the link travel time is predicted using the change in traffic supply and demand. Among these functions, the BPR link performance function has been adopted extensively in the traffic field to estimate the link (route) travel time in road network [8, 11, 19, 25-29]. For instance, Lo et al. [19] proposed the expected travel time (ETT)- and travel time budget (TTB)-based BPR functions to analyze travel time reliability. However, they only considered traffic capacity as a single source of uncertainty, and traffic capacity is independent of the amount of traffic in the BPR function. Based on this idea, Wang et al. [8] considered the formulation of a bi-objective perspective in Lo et al. [19] and proposed a general travel time reliability bi-objective user equilibrium model to analyze travel time variability based on the BPR function. $\mathrm{Ng}$ and Waller [11] assumed that the volume-delay function is provided by the BPR function to characterize travel time reliability using the fast Fourier transform. Later, Lo and Tung [26] considered traffic capacity as a particular probability density function in the BPR function and presented the Mellin transform to estimate the mean and variance of the travel time distribution. Li [30] investigated a fundamental problem in quantifying the travel time variability-based BPR function from its root sources, namely, stochastic capacity and demand variations that follow commonly used log-normal distributions. The proposed models provide theoretically rigorous and practically useful tools for understanding the causes of travel time unreliability and evaluating the system-wide benefit of reducing variability in demand and capacity. Therefore, the BPR function is beneficial and plays an important role in the study of travel time reliability. However, the previous research still has some deficiencies. In particular, fluctuation in demand and degradation of link capacity in the BPR function were either ignored completely or considered simply.

In this study, we attempt to estimate the link travel time considering the ratio of demand and capacity as a random variable in the proposed model based on the BPR function. Travel demand fluctuation or capacity degradation as a random variable of each influencing factor is considered separately in many studies. This study introduced the current degeneration coefficient of capacity (CDC) and the density distribution function of road section saturation (DDFS) to represent the effect of travel time uncertainty and avoid ignoring the relationships between them. Thus, the degradation of stochastic link capacity and stochastic demand will affect the value of the mean and the variance of the link travel time in an uncertain transportation network. Road section saturation as a random variable of travel time simplifies the BPR model and avoids the effect of factors that cannot be quantified on the traffic demand and supply. The CDC of each link may change every moment because of the uncertainty of the traffic environment. Thus, the CDC is stated as a variable of time dimension. Travelers want to ascertain the mean travel time of a selected route and need to know how much their chances are of arriving in their destination to avoid late arrivals within their TTB based on the mean-variance approach, which includes ETT and a travel time margin. Therefore, we propose the TTB model within a time-varying framework based on the BPR function to satisfy the requirements of punctual arrival based on the consideration of these uncertainty variables. Thereafter, the attraction of an optimal route choice involves the evaluation of the ETT and TTB. The improved model is proposed as a criterion of travel choice to obtain an optimal route from OD.

This paper is organized as follows:

(1) We present the ETT and TTB models based on the BPR function with fluctuations in demand and degradation of capacity.

(2) Capacity degradation as an endogenous variable affects the route travel time. Thus, we analyze the 
proposed ETT and TTB theoretically for sensitivity to degradation of capacity using the sensitivity analysis method.

(3) We show that the CDC and road section saturation have effects on travel time variability based on the proposed model by assuming two common distributions as normal and exponential for the DDFS and in the context of the mean-variance model as the main theoretical framework.

(4) Estimating the DDFS is an important issue in transportation. This study used the simplified vehicle speed data of morning rush hour to derive an estimation method for road section saturation based on traffic flow theory.

(5) A simple case study is conducted with real-world data from the Western 3rd Ring-Road Expressway to demonstrate and verify the proposed analytical model.

\section{Objectives and Contributions}

The objective of this study is to present a stochastic model based on the BPR link performance function and assess travel time reliability in the transportation network. We extend the application of the stochastic model by considering simultaneously the interaction between CDC and DDFS in the field of link/path travel time prediction. Case study and empirical analysis are also conducted to demonstrate the advantage of the proposed model. Results verified some practical implications regarding choice of route of drivers. This study also promoted the application of the road impedance function model in route choice and travel time estimation.

\section{Model}

The BPR function is adopted as the travel time of a link. The BPR function of a single link or corridor can be denoted as

$$
T_{a}=t_{a}^{0}\left[1+\beta\left(\frac{f_{a}}{c_{a}}\right)^{n}\right], \quad \forall a \in L,
$$

where the subscript $a$ refers to a particular link and $L$ is the set of directed links. $t_{a}^{0}$ is the travel time of link $a$ in free flow, and $c_{a}$ is the capacity of link $a$. We let $f_{a}$ denote the flow on the link $a$. Thus, we assumed that link $a$ of travel time function $T_{a}$ is associated with flow $f_{a}$ and capacity $c_{a}$. In addition, the parameters $\beta$ and $n$ are undetermined parameters.

In the traditional model, we assume that the capacity degradation random variable $c_{a}$ is independent of the amount of traffic (i.e., $f_{a}$ ) and neglect the capacity and traffic flow interacting with one another. In this study, by using road section saturation, the congestion level of the road section can be determined quickly. Thus, the DDFS usually appraises the real-time status of traffic jams in the complex traffic environment. The traveler should be able to obtain the distribution diagram of road section saturation along the route to estimate the travel time accurately. This study introduced the DDFS from this understanding.

We denote that $g\left(f_{a} / c_{a}\right)$ is the DDFS of road section saturation $f_{a} / c_{a}$, where all road section saturations on the study network are independent variables. However, road service level and traffic capacity are affected by various random factors, such as weather conditions and traffic accidents. Therefore, road section saturation is random and complex, thereby indicating that the design of traffic capacity is equal to the service rate in unit time, which will degenerate to a minimum with the worsening of the traffic environment. We then introduce the parameter $\phi_{a} \in[0,1]$, which implies that road section saturation $\varphi_{a}$ can denote the proportion of link traffic flow $f_{a}$ and link capacity $c_{a}$ with a degeneration coefficient $\phi_{a}$, that is, $\varphi_{a}=f_{a} / \phi_{a} c_{a}$. Here, road section saturation range is between 0 and $1 / \phi_{a}$, which can satisfy the possibility of oversaturation in the road section. For example, we assume that traffic capacity of a link is $1500 \mathrm{pcu} / \mathrm{h}$ and its traffic volume is $1200 \mathrm{pcu} / \mathrm{h}$. In general, bad weather and traffic accidents can lead to degradation of traffic capacity in urban roads. This phenomenon influences the road traffic network and decreases capacity in traffic networks. Therefore, the actual traffic capacity of a link may be reduced from $1500 \mathrm{pcu} / \mathrm{h}$ to $1000 \mathrm{pcu} / \mathrm{h}$. Then, worst-case stochastic link capacity degradation coefficient $\phi_{a}$ can be calculated as $\phi_{a}=1000(\mathrm{pcu} / \mathrm{h}) / 1500(\mathrm{pcu} / \mathrm{h})=2 / 3$. The corresponding link saturation is $\varphi_{a}=1200(\mathrm{pcu} / \mathrm{h}) / 1500(\mathrm{pcu} / \mathrm{h}) * 3 / 2=$ 1.2. That is, $\phi_{a}$ can be defined as the worst-case stochastic link capacity degradation coefficient and is also a variable of time dimension $t$ for each link. Intuitively, a higher value of $\phi_{a}$ corresponds to a shorter time for exiting from the link. Thus, we employed such variable to reflect the traffic status under the imbalance between traffic supply and demand in the degradation of the network.

Using the DDFS on the degree of degradation, we can derive the mean of the supply-demand dependent term of link $a$ travel time based on the expectation of a random variable as

$$
E\left(\varphi_{a}^{n}\right)=\int_{0}^{1 / \phi_{a}} \varphi_{a}^{n} g\left(\varphi_{a}\right) \mathrm{d} \varphi_{a}, \quad \forall a \in L,
$$

where $\int_{0}^{1 / \phi_{a}} g\left(\varphi_{a}\right) \mathrm{d} \varphi_{a}=1, \forall a \in L$. Here, the range of road section saturation is between 0 and $1 / \phi_{a}$ because of the possible occurrence of oversaturation in the link.

We then present a model based on the BPR function to assess the ETT of a route with fluctuation in demand and degradation of capacity in the transportation network. The ETT of the route represents how much time is expected to be spent. The following assumption was made to obtain the ETT of route based on the BPR function of link.

Assumption. The ETT of all links on the study network is independent of each other, as denoted by $E\left(T_{a}\right)$ for each link a.

Travelers will always want to minimize the ETT of the route. Let $T_{r}$ denote the route travel time on route $r$. 
Mathematically, the mean of $T_{r}$ can be calculated based on the aforementioned assumption as

$$
\begin{array}{r}
\min E\left(T_{r}\right)=\min \sum_{a \in L} \delta_{a}^{r}\left(t_{a}^{0}+t_{a}^{0} \beta \int_{0}^{1 / \phi_{a}} \varphi_{a}^{n} g\left(\varphi_{a}\right) \mathrm{d} \varphi_{a}\right), \\
a \in L, r \in R,
\end{array}
$$

where $\delta_{a}^{r}$ is the usual link-path incidence (i.e., $\delta_{a}^{r}=1$ ) if link $a$ belongs to path $r$ and 0 otherwise. The entire set of paths in the network is denoted by $R$.

Remark. In general, traffic jams on one link are likely to lead to congestion in upstream links considering the spatialtemporal correlation of traffic states. Therefore, link correlations have an influence on ETT in large-scale road networks. However, this assumption should be reasonable for the relatively minor network that this study aims to model. The distribution diagram of road section saturation also reflects the spatial-temporal evolution of traffic states in our study. Thus, the route travel time variable can be expressed by simply summing the corresponding link travel time variables.

However, travelers are concerned with the mean travel time and with satisfying the requirement of travel time reliability from OD. Degradation of network capacity causes travel time variability. Therefore, travelers do not know the exact prior travel times. Most travelers would depart early to allow for additional time or add a travel time margin to the expected trip time to avoid late arrivals [19]. Travelers are also concerned with travel time reliability when they are averse to risks. Therefore, travelers usually decide their route choice based on the TTB. The TTB represents how much time is needed for the trip. That is, travelers will provide a certain travel time margin to satisfy their requirements for punctual arrival.

In general, the TTB can be defined as [TTB]= $[\mathrm{ETT}]+[$ Travel Time Margin $]$, as shown in Figure 1 .

The TTB model can be expressed based on the meanvariance approach as

$$
\begin{array}{r}
B_{r}=E\left(T_{r}\right)+\rho \sqrt{\sum_{a \in L} \delta_{a}^{r}\left\{\beta^{2}\left(t_{a}^{0}\right)^{2}\left[E\left(\varphi_{a}^{2 n}\right)-E^{2}\left(\varphi_{a}^{n}\right)\right]\right\}}, \\
a \in L, r \in R,
\end{array}
$$

which is dependent on the level of risk aversion of an individual, measured by $\rho$, wherein the value of $\rho$ will always be greater than 0 and less than 2 [19].

Travelers usually want to minimize the ETT (i.e., $\left.\min E\left(T_{r}\right)\right)$ and also minimize the TTB:

$$
\begin{array}{r}
\min \left(E\left(T_{r}\right)+\rho \sqrt{\sum_{a \in L} \delta_{a}^{r}\left\{\beta^{2}\left(t_{a}^{0}\right)^{2}\left[E\left(\varphi_{a}^{2 n}\right)-E^{2}\left(\varphi_{a}^{n}\right)\right]\right\}}\right) \\
a \in L, r \in R
\end{array}
$$

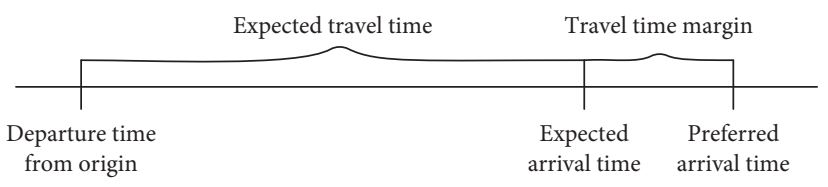

Figure 1: Schematic diagram of the TTB.

We consider the formulation from a bi-objective perspective. Thereafter, two objectives can be formulated as follows:

$$
\begin{aligned}
& \min E\left(T_{r}\right), \quad r \in R, \\
& \min \left(E\left(T_{r}\right)+\rho \sqrt{\sum_{a \in L} \delta_{a}^{r}\left\{\beta^{2}\left(t_{a}^{0}\right)^{2}\left[E\left(\varphi_{a}^{2 n}\right)-E^{2}\left(\varphi_{a}^{n}\right)\right]\right\}}\right), \\
& a \in L, r \in R .
\end{aligned}
$$

Therefore, a bi-objective model is presented in models (6) and (7) to provide the most reliable path in the transportation network. That is to say, these two objective functions are adopted as their travel choice criteria.

\section{Sensitivity Analysis of Capacity Degradation}

Although the change of road section saturation directly affects the link (route) travel time, in consideration of the capacity degradation as an endogenous variable for travel time variability, we only need sensitivity modeling for the capacity degradation to analyze the sensitivity of traffic capacity for the proposed ETT and TTB.

The impact of capacity degradation is reflected in the travel time. Therefore, modeling the sensitivity of capacity degradation by the increment of travel time with the increase of the CDC is suitable and general. The assumption is that the ETT and TTB are differentiable for the CDC. Then, we obtain the mathematical expression of the sensitivity of capacity degradation as

$$
\begin{aligned}
& \operatorname{sen}_{\mathrm{ETT}_{r}}^{w}=\frac{\partial\left(E\left(T_{r}, \phi_{a}+\Delta \phi_{a}\right)-E\left(T_{r}, \phi_{a}\right)\right)}{\partial \phi_{a}}, \quad \forall a, w, r, \\
& \underset{\operatorname{TTB}_{r}}{\operatorname{sen}^{w}}=\frac{\partial\left(B\left(\phi_{a}+\Delta \phi_{a}\right)-B_{r}\left(\phi_{a}\right)\right)}{\partial \phi_{a}}, \quad \forall a, w, r,
\end{aligned}
$$

where $\operatorname{sen}_{\mathrm{ETT}_{r}}^{w}\left(\operatorname{sTn}_{r} \operatorname{TT}^{w}\right)$ denotes the sensitivity of capacity degradation of the path $r$ about the ETT (TTB) in O/D pair $w$. Large sizes offer additional increments of ETT (TTB) of path $r$ with the increase of the CDC.

The sensitivity of ETT and TTB for the CDC are derived using (8) and (9): 


$$
\begin{aligned}
\operatorname{sen}_{\text {ETT }_{k}} & =\frac{\partial\left(\sum_{a \in L} \delta_{a}^{r} \beta t_{a}^{0}\left[\int_{0}^{1 /\left(\phi_{a}+\Delta \phi_{a}\right)} \varphi_{a}^{n} g\left(\varphi_{a}\right) \mathrm{d} \varphi_{a}-\int_{0}^{1 / \phi_{a}} \varphi_{a}^{n} g\left(\varphi_{a}\right) \mathrm{d} \varphi_{a}\right]\right)}{\partial \phi_{a}} \\
& =\sum_{a \in L} \delta_{a}^{r} \beta t_{a}^{0}\left[\left(\frac{1}{\phi_{a}}\right)^{n+2} g\left(\frac{1}{\phi_{a}}\right)-\left(\frac{1}{\phi_{a}+\Delta \phi_{a}}\right)^{n+2} g\left(\frac{1}{\phi_{a}+\Delta \phi_{a}}\right)\right], \\
\operatorname{sTB}_{\operatorname{sTn}_{k}}^{w} & =\frac{\partial\left(B\left(\phi_{a}+\Delta \phi_{a}\right)-B_{r}\left(\phi_{a}\right)\right)}{\partial \phi_{a}}=\operatorname{sen}_{\operatorname{sTT}_{k}}+\Theta,
\end{aligned}
$$

where

$$
\begin{aligned}
& \Theta=\rho \sum_{a \in L} \delta_{a}^{r}\left(\beta t_{a}^{0}\right)^{2}\left[g\left(\frac{1}{\phi_{a}+\Delta \phi_{a}}\right) \frac{2\left(1 / \phi_{a}+\Delta \phi_{a}\right)^{n+2}-\left(1 / \phi_{a}+\Delta \phi_{a}\right)^{2 n+2}}{2 \Pi}-\frac{2\left(1 / \phi_{a}\right)^{n+2}-\left(1 / \phi_{a}\right)^{2 n+2}}{2 \Upsilon} g\left(\frac{1}{\phi_{a}}\right)\right], \\
& \Upsilon=\sqrt{\sum_{a \in L} \delta_{a}^{r}\left(\beta t_{a}^{0}\right)^{2}\left(\int_{0}^{1 /\left(\phi_{a}+\Delta \phi_{a}\right)} \varphi_{a}^{2 n} g\left(\varphi_{a}\right) \mathrm{d} \varphi_{a}-\left(\int_{0}^{1 /\left(\phi_{a}+\Delta \phi_{a}\right)} \varphi_{a}^{n} g\left(\varphi_{a}\right) \mathrm{d} \varphi_{a}\right)^{2}\right)} \\
& \Pi=\sqrt{\sum_{a \in L} \delta_{a}^{r}\left(\beta t_{a}^{0}\right)^{2}\left(\int_{0}^{1 /\left(\phi_{a}+\Delta \phi_{a}\right)} \varphi_{a}^{2 n} g\left(\varphi_{a}\right) \mathrm{d} \varphi_{a}-\left(\int_{0}^{1 /\left(\phi_{a}+\Delta \phi_{a}\right)} \varphi_{a}^{n} g\left(\varphi_{a}\right) \mathrm{d} \varphi_{a}\right)^{2}\right)} .
\end{aligned}
$$

Figure 2 shows that the DDFS increases monotonically with the increase of road section saturation in the left interval of $\varphi^{*}$. In contrast, the DDFS decreases monotonically with the increase of road section saturation in the right interval of $\varphi^{*}$.

The following propositions can be obtained based on the analysis.

Proposition 1. The sensitivity of the ETT model for CDC is displayed as follows: The ETT performs higher sensitivity for the CDC in increasing interval of DDFS; otherwise, the sensitivity of ETT for the CDC is weakened in decreasing interval of DDFS.

Proof. In accordance with (3), the ETT is strictly decreasing monotonously with the increase of the CDC, i.e., $\partial \mathrm{ETT} / \partial \phi_{a}<0$. When road section saturation belongs to the increasing interval of DDFS, as well as $g^{\prime \prime}(\varphi) \geq 0$, it obtains that $\operatorname{sen}_{\text {ETT }_{k}}^{w}$ and $\phi_{a}$ have a negative correlation according to (10). Then, $\phi_{a}$ is decreasing monotonously with $\operatorname{sen}^{w}$. One conclusion can be drawn that the ETT performs higher sensitivity for the CDC in an increasing interval of DDFS based on $\partial \mathrm{ETT} / \partial \operatorname{sen}^{w} \geq 0$. Otherwise, when $\operatorname{road}$ section saturation belongs to a decreasing interval of DDFS and $g^{\prime \prime}(\varphi)<0$, and then, $\phi_{a}$ is increasing monotonously with $\underset{\text { ETT }_{k}}{\operatorname{sen}^{w}}$ in accordance with $\partial \operatorname{sen}_{k}^{w} / \partial \phi_{a} \geq 0$. The result of $\partial \mathrm{ETT} / \partial \operatorname{sen}^{w} \leq 0$ is derived. Therefore, the sensitivity of ETT for the CDC is weakened in decreasing interval of DDFS. This completes the proof.

Proposition 2. Under the sensitivity preference of ETT model for CDC, the sensitivity of TTB model for CDC is represented as follows: The TTB model performs with higher sensitivity for the CDC in increasing interval of DDFS; in contrast, the sensitivity of TTB model for the CDC is weakened in decreasing interval of DDFS.

Proof. Differentiating the two sides of (5) for $\phi_{a}$, we have

$$
\begin{aligned}
\frac{\partial \mathrm{TTB}}{\partial \phi_{a}} & =\sum_{a \in L} \delta_{a}^{r} \beta t_{a}^{0}\left[-1+\frac{\left[-\phi_{a}^{-n}+2\left(\int_{0}^{1 / \phi_{a}} \varphi^{n} g(\varphi) \mathrm{d} \varphi\right)\right]}{\sqrt{\int_{0}^{1 / \phi_{a}} \varphi^{2 n} g(\varphi) \mathrm{d} \varphi-\left(\int_{0}^{1 / \phi_{a}} \varphi^{n} g(\varphi) \mathrm{d} \varphi\right)^{2}}}\right] \phi_{a}^{-n-2} g\left(\frac{1}{\phi_{a}}\right) \\
& \leq-\frac{1}{2} \sum_{a \in L} \delta_{a}^{r} \beta t_{a}^{0}<0 .
\end{aligned}
$$




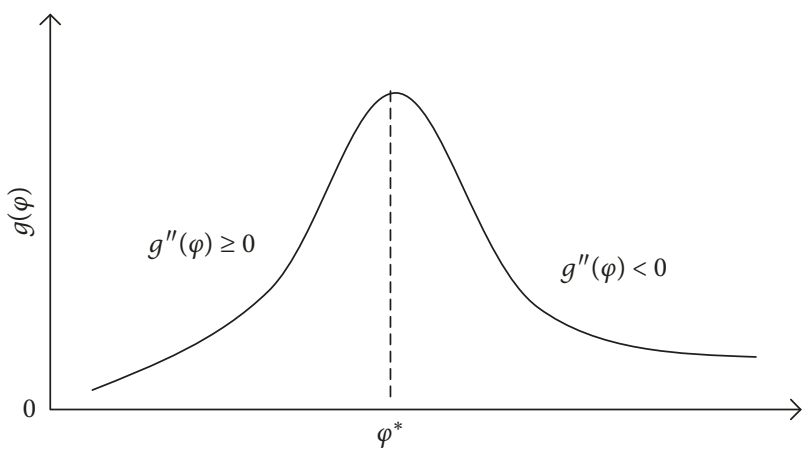

FIGURE 2: Graphical representation of the DDFS.

Then, it shows that the TTB is strictly decreasing monotonously with the increase of CDC. When road section saturation belongs to the increasing interval of DDFS and $g^{\prime \prime}(\varphi) \geq 0$, we can obtain that $\operatorname{sTB}_{k}^{w}$ and $\Theta$ also have a negative correlation. In accordance with Proposition 1 and $\underset{\text { TTB }_{k}}{\operatorname{sen}^{w t}=\operatorname{sen}_{\text {ETT }} \operatorname{sen}^{w}}+\Theta$, as well as $\phi_{a}$ is decreasing monotonously with $\operatorname{sen}_{\mathrm{ETT}_{k}}^{w}, \phi_{a}$ is decreasing monotonously with $\operatorname{sTB}_{k} \operatorname{sen}_{k}$. Thus, the TTB model performs with higher sensitivity for the CDC in an increasing interval of DDFS based on the conclusion of $\partial \mathrm{TTB} / \partial \operatorname{sTn}^{w} \geq 0$. Otherwise, when road section saturation belongs to decreasing interval of DDFS and $g^{\prime \prime}(\varphi)<0$, we know that $\phi_{a}$ is increasing monotonously with $\operatorname{sen}_{\mathrm{ETT}_{k}}{ }^{w}$ based on Proposition 1, and $\operatorname{sen}_{\mathrm{TTB}_{k}}^{w}$ and $\Theta$ also have a positive correlation in accordance with $\partial \Theta / \partial \phi_{a} \geq 0$. Then, we can obtain that the sensitivity of TTB for the CDC is weakened in decreasing interval of DDFS based on $\partial \mathrm{TTB} / \partial \operatorname{\mathrm {TTB}}_{k}{ }^{w} \leq 0$. This completes the proof.

Propositions 1 and 2 show that the ETT and TTB models have a higher sensitivity for the CDC in a state of sparse traffic flow, whereas the sensitivity of ETT and TTB is weakened with increasing road section saturation when the traffic flow is in a state of saturation or oversaturation. This result is consistent with our intuition, as well as explains the impact of DDFS and CDC for the ETT and TTB in theory.

Next, we will give some illustrative examples and verify the results of Propositions 1 and 2, as well as the impact of the DDFS and CDC for the traveler's decision regarding the choice of route based on the proposed ETT and TTB models by using the MATLAB tool.

\section{Illustrative Examples}

Generally, the travel time experienced by travelers is subject to different disturbances on the road (e.g., random accidents, routine road maintenance, natural disasters, special events, or bad weather) [31]. These relatively minor events occur quite frequently in our daily travel, increasing the degradations of stochastic link capacity, which constitute the source of travel time variations. The CDC of each link may change every moment because of the uncertainty of traffic environment. In addition, the DDFS has significant effects on travel time from OD with the time-varying traffic demand and supply. Therefore, the DDFS and CDC for each link have a considerable influence on the ETT and TTB based on the analysis of the previous section (Propositions 1 and 2).

The proposed models with fluctuation in demand and degradation of capacity are adopted as the criteria for the traveler's route decision. Therefore, travelers should consider the influence of the DDFS and CDC of the link within the process of deciding route choice.

5.1. Four-Parallel Route Network. Consider the example depicted in Figure 3, comprising two nodes $O$ and $D$, four paths $1,2,3$, and 4 , and a single $O / D$ pair $w=(O, D)$.

Without loss of generality, we assume that the DDFS follows two common distributions in this test example, namely, normal and exponential. However, the specific shape distribution of road section saturation must investigate the road section saturation by traffic flow data.

The TTB for each path is represented by the summation of three parts (i.e., the free-flow travel time (FFTT), the waiting time (TWT), and the buffer time (TBT)), as shown in Figure 4. Travelers are usually concerned with the ETT and consider the effect of late arrival. Thus, travelers prefer considering the TTB rather than the ETT. The analyzed results reveal that different route choice criteria, such as the ETT and TTB, provide different travel routes. Table 1 shows that travelers should spend additional ETT and TTB from $O$ and $D$ if they choose Path 3 compared with Path 2 . Similarly, if travelers choose Path 4 instead of Path 1, they should spend additional ETT and TTB from $O$ and $D$. Results show that the ETT and TTB of path change with the change in the CDC of the path changed. The implication is that the CDC has significant effects on travel time and its reliability. It also reflects the CDC and DDFS toward the effects of the preferences in the decision process of route choice, as shown in Figure 4. Observe that travelers on Path 4 may experience a higher TWT than those on other paths. Those worse cases are mainly caused by various sources, such as bad weather conditions, incidents, and other special events, which lead to deteriorating links and increasing road section saturation. Then, the path of travel time will increase with the formation of traffic congestion points in these situations. Therefore, two aspects of influencing factors for route should be considered in the process of choosing a route.

For instance, considering the DDFS with normal distribution $\varphi \in N(0.5,0.25)$ and the FFTT of 23 minutes as shown in Table 1, we can obtain that the sensitivity of ETT is 0.02 for CDC when the CDC varies from 0.3 to 0.4 , and the sensitivity of ETT is 0.38 for CDC when the CDC varies from 0.4 to 0.5 . We can also obtain that the sensitivity of ETT is 0.548 for CDC when the CDC varies from 1 to 1.1 , and the value of sensitivity of ETT is 0.364 for CDC when the CDC varies from 1.1 to 1.2. Although the CDC has the same increment in these two intervals (increasing and decreasing intervals of the DDFS), as described in Proposition 1, the proposed ETT model is more sensitive to the CDC in increasing interval of the DDFS, and the proposed ETT model 


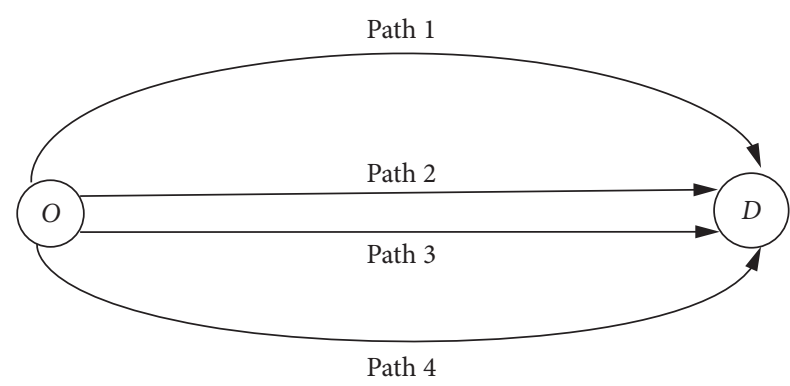

FIgURE 3: Four-link example network.

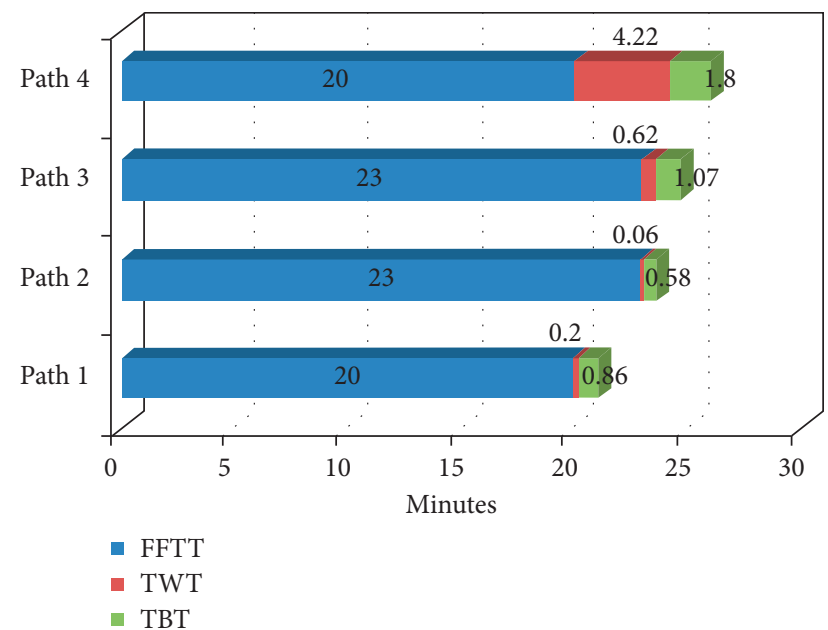

Figure 4: Analysis of the effects of travel time variability.

TABLE 1: Results of the proposed ETT and TTB in the corresponding path parameters.

\begin{tabular}{lcccccccc}
\hline Path & FFTT & DDFS & $\beta$ & $n$ & $\rho$ & $\phi_{a}$ & ETT & TTB \\
\hline 1 & 20 & $\varphi \in E(0.5)$ & 0.15 & 4 & 1 & 1 & 20.20 & 21.06 \\
2 & 23 & $\varphi \in N(0.5,0.25)$ & 0.15 & 4 & 1 & 1 & 23.06 & 23.64 \\
3 & 23 & $\varphi \in N(0.5,0.25)$ & 0.15 & 4 & 1 & $1 / 2$ & 23.62 & 24.69 \\
4 & 20 & $\varphi \in E(0.5)$ & 0.15 & 4 & 1 & $1 / 2$ & 24.22 & 26.02 \\
\hline
\end{tabular}

is less sensitive to the CDC in decreasing interval of the DDFS. Likewise, the results of this analysis are also well suited to Proposition 2.

Therefore, travelers can select the optimal routes from OD and depart at an appropriate time after being aware of the DDFS in the road. Notably, the CDC of the link affects the DDFS, thereby influencing the ETT and TTB. An optimal routing example is presented in the next section to highlight this point.

5.2. Small Network for Optimal Routing. The proposed TTB model is applied for analyzing a small network with 9 nodes and 15 links (see Figure 5), where OD is from nodes 1 to 9 . We assume that the DDFS of the link follows an exponential distribution in this test case. However, the actual traffic capacity of each link varies at a provided time in different traffic environments. The link parameters are specified in Table 2 .

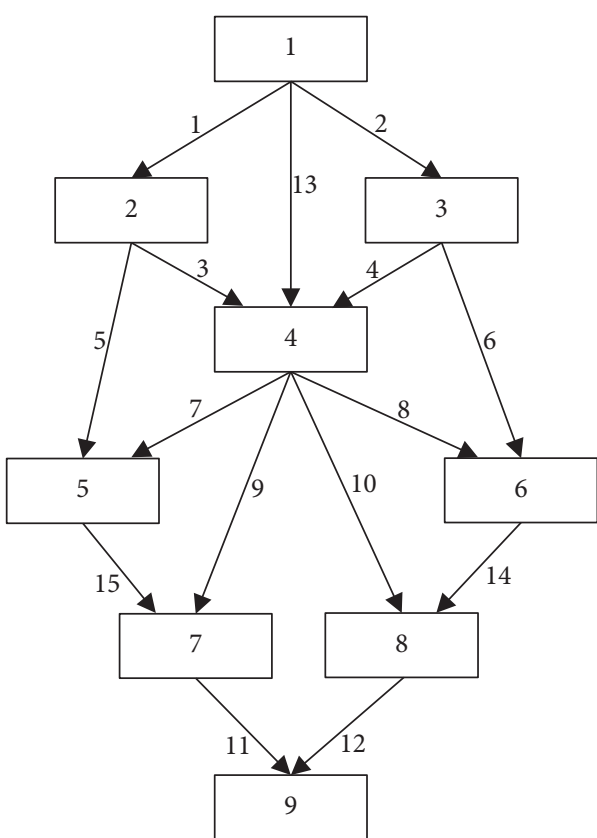

FIGURE 5: Small network.

TABLE 2: Link characteristics of the small network.

\begin{tabular}{lccc}
\hline Link & FFTT & CDC & DDFS \\
\hline 1 & 15 & 0.3 & $E(0.5)$ \\
2 & 20 & 0.7 & $E(1.2)$ \\
3 & 30 & 0.8 & $E(0.6)$ \\
4 & 20 & 0.5 & $E(1)$ \\
5 & 14 & 0.2 & $E(2.3)$ \\
6 & 17 & 0.4 & $E(1.6)$ \\
7 & 20 & 0.2 & $E(1.4)$ \\
8 & 32 & 0.9 & $E(1.8)$ \\
9 & 28 & 0.8 & $E(0.7)$ \\
10 & 30 & 0.7 & $E(1)$ \\
11 & 14 & 0.2 & $E(1.2)$ \\
12 & 25 & 0.7 & $E(0.5)$ \\
13 & 20 & 0.4 & $E(1.1)$ \\
14 & 25 & 0.6 & $E(2)$ \\
15 & 21 & 0.7 & $E(1.4)$ \\
\hline
\end{tabular}

Travelers employ two ways to obtain information about each link to select the optimal route (i.e., (1) the entire network information before departure and (2) the subsequent path information in the current junction).

Therefore, the shortest path algorithm is adopted to select the optimal route for the two preceding strategies.

Strategy 1. The objective function is $\sum_{a \in L} \delta_{a}^{r}$ TTB. The shortest path algorithm (Dijkstra algorithm) is presented to solve the objective function. Figure 6(a) shows that the optimal route is $1-4-8-9$, and the least TTB is $90.33 \mathrm{~min}$ in the entire network from nodes 1 to 9 .

Strategy 2. If the travelers only possess information about the current junction, then they can make the best decisions based on the corresponding links of the current node, which 


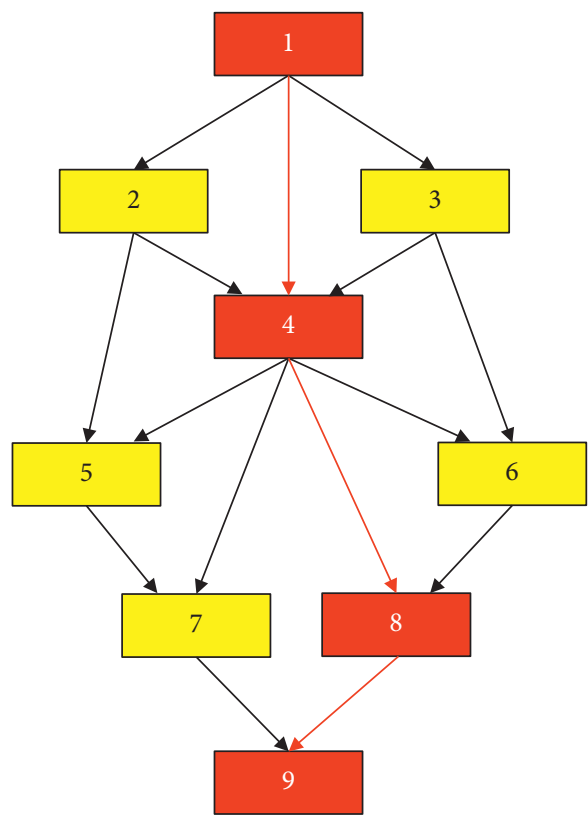

(a)

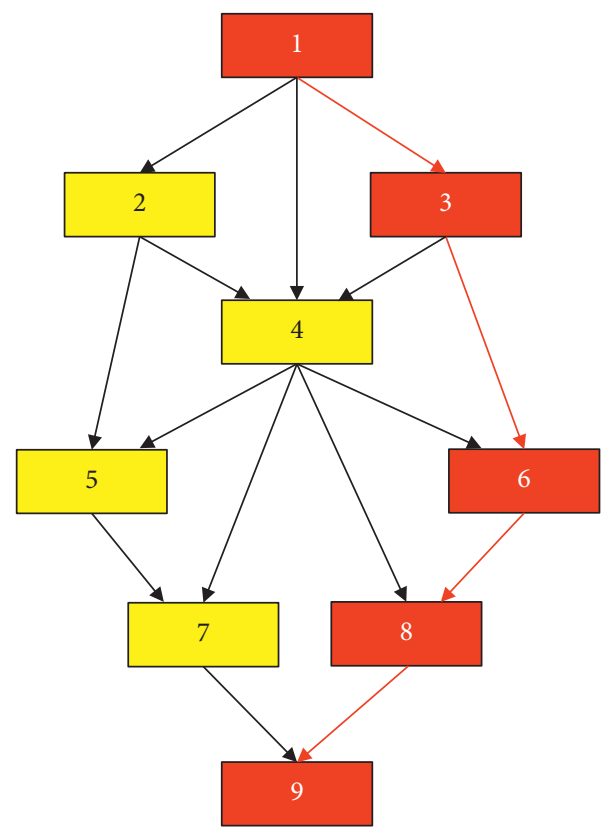

(b)

Figure 6: Graphic of the shortest path.

are connected to the next node. Thereafter, Figure 6(b) was obtained via the Dijkstra algorithm. In this strategy, the travelers will obtain the optimal route as $1-3-6-8-9$, and the least TTB is $101.3 \mathrm{~min}$.

Figure 7 shows that the travel time of Strategy 1 is less than that of Strategy 2. The travelers may not choose node 4 as an alternative node for a trip when the CDC of link 10 varies from 0.7 to 0.2 . If the travelers also select $1-4-8-9$ as the optimum trip route, then they will spend additional TTB (i.e., $\left.\sum_{a \in L} \delta_{a}^{r} \mathrm{TTB}=151.33\right)$. Therefore, hedging the risks of realtime traffic changes, the best route choice is Strategy 2. This example provides a remarkable illustration of the influence of CDC in a time-varying transportation system, which affects the behavioral characteristics of travelers when choosing the route for travel. Moreover, a conclusion can be drawn that the DDFS is important for travelers when choosing routes.

\section{Calibrating the DDFS by an Approximate Evaluation}

The stochastic model of the ETT and TTB are affected by road section saturation. Therefore, estimating the DDFS is particularly important. The proposed model is a function of road section saturation. Road section saturation is the ratio of the actual traffic volume and the design traffic capacity based on the BPR function. Obtaining road saturation data is difficult in actual traffic situations. However, space mean speed of the link is easily collected by using a floating car with an information-collecting technology. Then, we can obtain road section saturation using traffic flow theory.

A linear relation expression of the three parameters of traffic flow is adopted as follows:

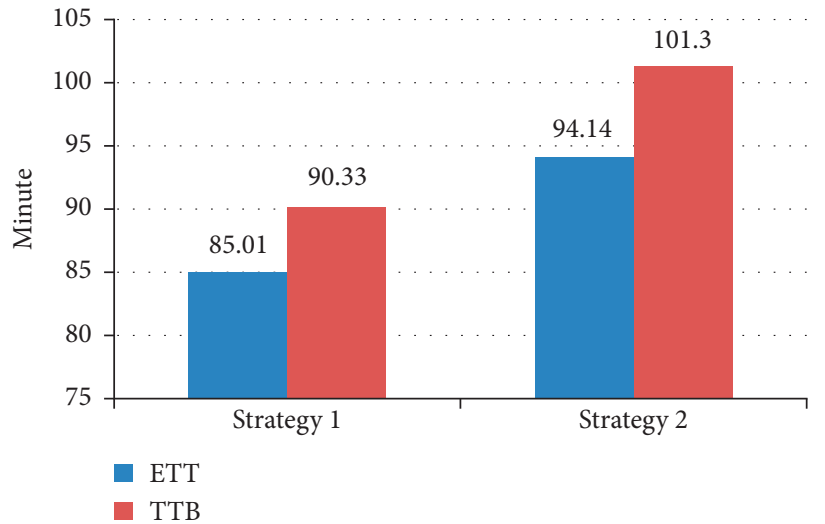

Figure 7: Value of ETT and TTB in the two strategies.

$$
\left\{\begin{array}{l}
v=v_{f}\left(1-\frac{k}{k_{j}}\right), \\
f=k v
\end{array}\right.
$$

where $v$ is space mean speed, $k$ is the traffic density, $v_{f}$ is the free-flow speed, $f$ is the traffic flow, and $k_{j}$ is the jam density.

We can substitute the relationship of $v$ and $v_{f}$ for $f / c$, considering the lower bound to be a fraction $\phi_{a}$ of the design capacity:

$$
\begin{array}{r}
\frac{f}{c} \approx \frac{f}{\phi_{a} q_{m}}=\frac{k v}{\phi_{a} q_{m}}=\frac{v k_{j}\left(1-\left(v / v_{f}\right)\right)}{1 / 4 \phi_{a} k_{j} v_{f}}=4 \frac{v}{\phi_{a} v_{f}}\left(1-\left(\frac{v}{v_{f}}\right)\right), \\
0<\phi_{a} \leq 1, v \geq \frac{1}{2} v_{f},
\end{array}
$$


where $q_{m}$ is the maximum service traffic volume of the link, which is usually similar to the design traffic capacity.

From the preceding analysis, reasonable and effective direct estimation of the effects of CDC and DDFS on the choice of travel route is an important issue in transportation. Therefore, the data used for evaluating the DDFS were floating car speeds collected in the Liuliqiao district, Beijing for the following study. Liuliqiao district includes Xinxing Bridge in the north, southward to Lize Bridge in the south, Baolian Road in the west, eastward to Honglian South Road in the east, with a total of 1005 nodes in the region. Liuliqiao is the exit of JingShi Expressway, a comprehensive transportation hub with interprovincial passenger transport as the main part, and its traffic flow is relatively large. The road speed limit is $80 \mathrm{~km} / \mathrm{h}$, the free-flow speed is approximately $68.4 \mathrm{~km} / \mathrm{h}$, and the jamming density is within the range of $115 \mathrm{veh} / \mathrm{km}-155 \mathrm{veh} / \mathrm{km}$. The data were collected in a span of four weeks in 2013, including two weeks in March and two weeks in September, excluding weekends. First, missing data were replaced with data from the same period as collected on other days in the preprocessing of floating car speed data. Second, linear interpolation calculation was performed with adjacent time steps if data remained missing. The abnormal data for certain road segments, excluding those in the $95 \%$ confidence interval range, were identified from all speeds at the same time of day. Third, the speed data are time-mean average speed at every five minutes in each segment. Considering the fact that space mean average speed can substantially characterize the state of the segments, the floating car time-mean speeds were converted to space mean speeds of each segment based on the time and space mean speed relationship [32]. In the evaluation, a case study on the road section from the Western 3rd Ring-Road Expressway is conducted. The path from Xinxingqiao to Lizeqiao was divided into several segments in accordance with on- and off-ramps. The length of the segments was also obtained. In the case study, the different road sections have different morning peak hours. Therefore, the effective data were selected in a span of 20 weekdays between $6: 30$ and 9:30 AM. The topology of the selected road sections is shown in Figure 8.

This study selected several frequently used distributions as generalized extreme value, uniform, and normal to determine the optimal DDFS for the Liuliqiao data. We determined and compared the Kolmogorov-Smirnov (K-S) statistics of the selected distributions based on the floating car speed data. We choose about sixty distribution functions to fit DDFS. Among them, the K-S statistics of some common distribution functions are listed in Table 3.

According to the $\mathrm{K}-\mathrm{S}$ statistic, a small value for $\mathrm{K}-\mathrm{S}$ statistic indicates the high goodness of fit. Table 3 shows that the $\mathrm{K}-\mathrm{S}$ statistic of generalized extreme value distribution is less than the K-S statistic of other distributions. Moreover, by taking an example of this link from node ID 11215 to node ID 11163, the DDFS follows the generalized extreme value distribution as shown in Figure 9. The P-P plot of Figure 10 shows that the data satisfy the generalized extreme value distribution function because each point approximates a straight line, which also shows that the DDFS is more in

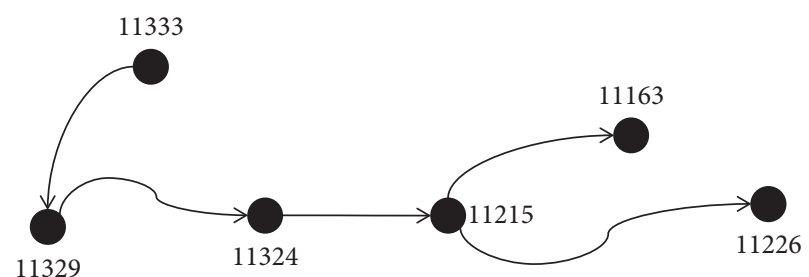

FIgURE 8: Diagrammatic sketch of the selected road sections with node ID.

accordance with the generalized extreme value distribution compared with other distributions, such as normal, Johnson SB, and Weibull. Therefore, we have sufficient evidence to accept this result, in which the DDFS follows the generalized extreme value distribution in the Western 3rd Ring-Road Expressway during the morning rush hour.

The generalized extreme value of the DDFS is provided as

$$
\begin{aligned}
g\left(\varphi_{a} ; \kappa_{a}, \mu_{a}, \sigma_{a}\right)= & \frac{1}{\sigma_{a}}\left[1+\kappa_{a}\left(\frac{\varphi_{a}-\mu_{a}}{\sigma_{a}}\right)\right]^{\left(-1 / \kappa_{a}\right)-1} \\
& \times \exp \left\{-\left[1+\kappa_{a}\left(\frac{\varphi_{a}-\mu_{a}}{\sigma_{a}}\right)\right]^{\left(-1 / \kappa_{a}\right)}\right\},
\end{aligned}
$$

where $1+k_{a}\left(\varphi_{a}-\mu_{a}\right) / \sigma_{a}>0$; the subscript $a$ refers to a particular link. $\mu_{a}, \sigma_{a}>0$, and $\kappa_{a}$ denote the location parameter, range parameter, and shape parameter of link $a$, respectively. We must acquire the three preceding parameters of the generalized extreme value for each link by actual data calculations because road section saturation is different from each other during the morning rush hour.

Theoretically, we can obtain the following models to estimate the ETT and TTB during the morning rush hour.

$$
\begin{array}{r}
E\left(T_{r}\right)=\sum_{a \in L} \delta_{a}^{r}\left(t_{a}^{0}+t_{a}^{0} \beta \int_{0}^{1 / \phi_{a}} \varphi_{a}^{n} g\left(\varphi_{a}\right) \mathrm{d} \varphi\right), \\
a \in L, r \in R, \\
B_{r}=E\left(T_{r}\right)+\rho \sqrt{\sum_{a \in L} \delta_{a}^{r}\left(\beta t_{a}^{0}\right)^{2}\left[E\left(\varphi_{a}^{2 n}\right)-E^{2}\left(\varphi_{a}^{n}\right)\right]}, \\
a \in L, r \in R,
\end{array}
$$

$$
\begin{aligned}
g\left(\varphi_{a} ; \kappa_{a}, \mu_{a}, \sigma_{a}\right)= & \frac{1}{\sigma_{a}}\left[1+\kappa_{a}\left(\frac{\varphi_{a}-\mu_{a}}{\sigma_{a}}\right)\right]^{\left(-1 / \kappa_{a}\right)-1} \\
& \times \exp \left\{-\left[1+\kappa_{a}\left(\frac{\varphi_{a}-\mu_{a}}{\sigma_{a}}\right)\right]^{-1 / \kappa_{a}}\right\} .
\end{aligned}
$$

\section{Empirical Analysis}

Travel time variability is tremendous during the morning rush hour. Thus, travelers are concerned with their TTB to 
TABLE 3: Statistical results of DDFS for five links.

\begin{tabular}{|c|c|c|}
\hline Distribution & K-S statistic & $\alpha=0.05$ (should be rejected) \\
\hline $\begin{array}{l}\text { From node ID } 11333 \text { to node ID } 11329 \\
\text { Generalized extreme value } \\
\text { Johnson SB } \\
\text { Log-normal } \\
\text { Weibull } \\
\text { Uniform } \\
\text { Normal } \\
\text { Exponential } \\
\text { Pareto }\end{array}$ & $\begin{array}{c}0.03677 \\
0.04412 \\
0.14788 \\
0.08799 \\
0.12405 \\
0.10575 \\
0.33625 \\
\text { No fit }\end{array}$ & $\begin{array}{l}\text { No } \\
\text { No } \\
\text { Yes } \\
\text { Yes } \\
\text { Yes } \\
\text { Yes } \\
\text { Yes }\end{array}$ \\
\hline $\begin{array}{l}\text { From node ID } 11329 \text { to node ID } 11324 \\
\text { Generalized extreme value } \\
\text { Johnson SB } \\
\text { Weibull } \\
\text { Uniform } \\
\text { Normal } \\
\text { Exponential } \\
\text { Pareto } \\
\text { Lognormal }\end{array}$ & $\begin{array}{c}0.03187 \\
0.03557 \\
0.0497 \\
0.08323 \\
0.06734 \\
\text { No fit } \\
\text { No fit } \\
\text { No fit }\end{array}$ & $\begin{array}{l}\text { No } \\
\text { No } \\
\text { No } \\
\text { Yes } \\
\text { Yes }\end{array}$ \\
\hline $\begin{array}{l}\text { From node ID } 11324 \text { to node ID } 11215 \\
\text { Generalized extreme value } \\
\text { Johnson SB } \\
\text { Lognormal } \\
\text { Weibull } \\
\text { Uniform } \\
\text { Normal } \\
\text { Exponential } \\
\text { Pareto }\end{array}$ & $\begin{array}{c}0.04594 \\
0.0474 \\
0.17705 \\
0.19495 \\
0.09964 \\
0.12087 \\
0.36142 \\
0.5329\end{array}$ & $\begin{array}{l}\text { No } \\
\text { No } \\
\text { Yes } \\
\text { Yes } \\
\text { Yes } \\
\text { Yes } \\
\text { Yes } \\
\text { Yes }\end{array}$ \\
\hline $\begin{array}{l}\text { From node ID } 11215 \text { to node ID } 11163 \\
\text { Generalized extreme value } \\
\text { Johnson SB } \\
\text { Lognormal } \\
\text { Weibull } \\
\text { Uniform } \\
\text { Normal } \\
\text { Exponential } \\
\text { Pareto }\end{array}$ & $\begin{array}{c}0.02612 \\
0.02659 \\
0.11333 \\
0.06051 \\
0.09492 \\
0.06977 \\
0.4452 \\
0.44823 \\
\end{array}$ & $\begin{array}{l}\text { No } \\
\text { No } \\
\text { Yes } \\
\text { Yes } \\
\text { Yes } \\
\text { Yes } \\
\text { Yes } \\
\text { Yes }\end{array}$ \\
\hline $\begin{array}{l}\text { From node ID } 11215 \text { to node ID } 11226 \\
\text { Generalized extreme value } \\
\text { Johnson SB } \\
\text { Lognormal } \\
\text { Weibull } \\
\text { Uniform } \\
\text { Normal } \\
\text { Exponential } \\
\text { Pareto }\end{array}$ & $\begin{array}{c}0.04005 \\
0.04017 \\
0.20991 \\
0.11225 \\
0.117 \\
0.11733 \\
0.32285 \\
\text { No fit }\end{array}$ & $\begin{array}{l}\text { No } \\
\text { No } \\
\text { Yes } \\
\text { Yes } \\
\text { Yes } \\
\text { Yes } \\
\text { Yes }\end{array}$ \\
\hline
\end{tabular}

make a trip during the morning peak. In this case, travelers can choose their departure times or travel routes so that late arrivals at the destinations can be avoided. For this particular case, if travelers want to complete a journey from node IDs 11333 to 11163 (or 11226) during morning rush hour, then the TTB estimation can be obtained by equation (17). The three parameters of the generalized extreme value distribution for all related links in the morning peak are obtained by actual data calculations, as shown in Table 4 .

$\beta$ and $n$ are the undetermined parameters in the proposed TTB model of equation (17). We know that the recommended values $(\beta=0.15$ and $n=4)$ of the BPR function are advanced by the US Highway Bureau. However, the undetermined parameters always yield poor results in several engineering practices in China [33]. Thus, we calibrated the two parameters in this study based on the data of the Western 3rd Ring-Road Expressway. The value of $\beta$ and $n$ are obtained as 0.56 and 2.12, respectively. We also assumed that all links are independent of each other and are identical distributions. We determined that Lindeberg's condition $[34,35]$ satisfies the random variable $T_{a}$. The route travel time converges to a normal distribution based on the central limit theorem. Then, we give parameter $\lambda=\Phi^{-1}(\alpha)$, where $\alpha$ is confidence level. $\lambda=0$ of the model of equation (17) implies a confidence level of $\alpha=0.5$ for TTB, which indicates the travelers are the ETT decision-makers because they select 


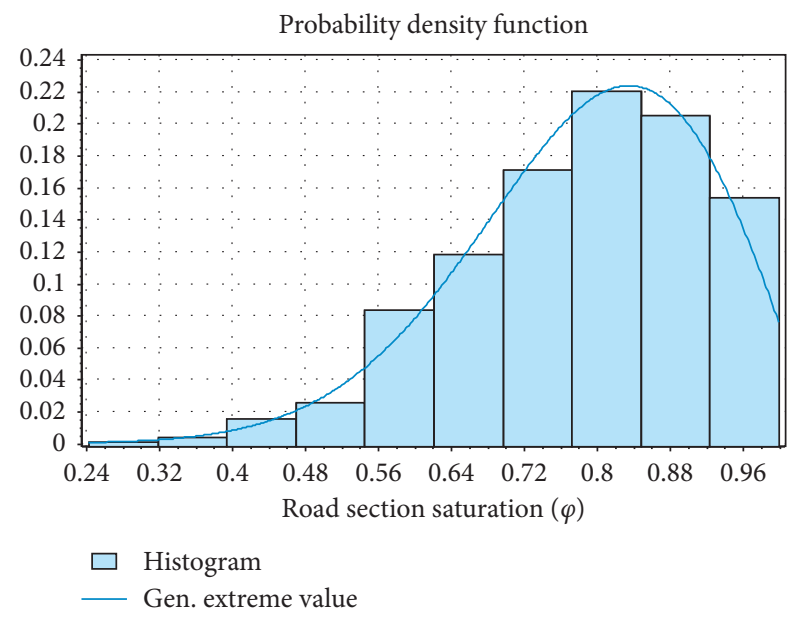

FIGURE 9: Generalized extreme value probability density function for node IDs 11215 to 11163 .

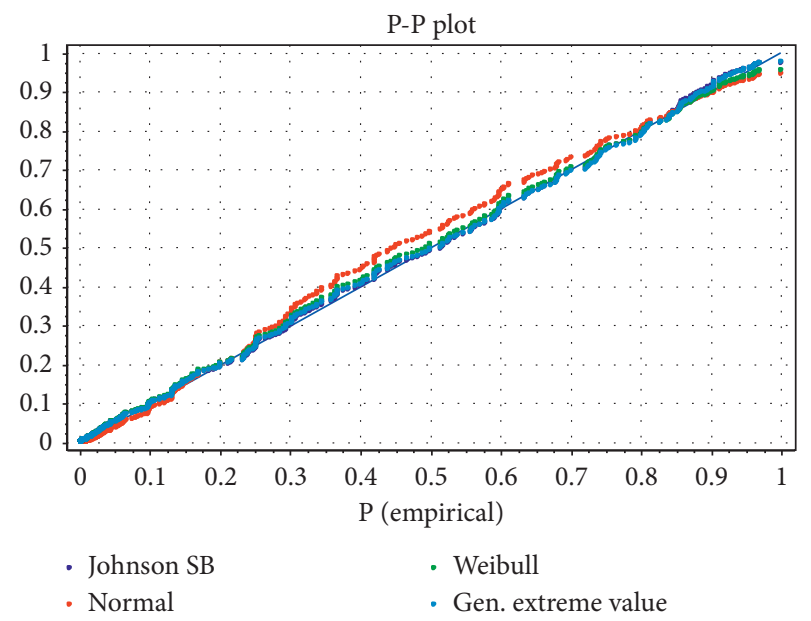

Figure 10: P-P plots of four types of cumulative distribution and the corresponding observed value of cumulative distribution.

TABle 4: Estimation parameters for general extreme value distribution.

\begin{tabular}{lcccc}
\hline From (node ID) & To (node ID) & $\kappa$ & $\sigma$ & $\mu$ \\
\hline 11333 & 11329 & -0.6914 & 0.2457 & 0.67505 \\
11329 & 11324 & -0.47127 & 0.23465 & 0.59767 \\
11324 & 11215 & -0.54705 & 0.13958 & 0.77726 \\
11215 & 11163 & -0.49128 & 0.14439 & 0.75264 \\
11215 & 11226 & -0.67386 & 0.26009 & 0.64846 \\
\hline
\end{tabular}

routes to minimize their mean travel times. $\lambda=1.64$ implies that travelers have a $\alpha=0.95$ chance of arriving within their TTB.

Using the proposed model, the TTB and ETT are estimated in the case of Figure 8, as shown in Table 5.

Table 5 summarizes the resulting estimates and the errors of OVMTT and TTB, in which the mean absolute percentage error (MAPE) is calculated for each estimate. To illustrate, MAPE is calculated as follows:
TABLE 5: Estimated and observed values of mean travel time (OVMTT) for each link.

\begin{tabular}{ccccccc}
\hline \multicolumn{2}{c}{ Link no. } & \multicolumn{3}{c}{$\lambda=0$} & $\lambda=1.64$ & \multicolumn{2}{c}{$\lambda=3.89$} \\
From & To & OVMTT (s) & TTB (s) & TTB (s) & TTB (s) & $\begin{array}{c}\text { Error } \\
(\%)\end{array}$ \\
\hline 11333 & 11329 & 2.675 & 1.996 & 2.285 & 2.682 & 0.26 \\
11329 & 11324 & 2.758 & 2.132 & 2.386 & 2.734 & 0.87 \\
11324 & 11215 & 44.589 & 34.735 & 38.187 & 42.925 & 2.73 \\
11215 & 11163 & 9.515 & 6.776 & 7.436 & 8.341 & 12.34 \\
11215 & 11226 & 8.453 & 6.422 & 7.287 & 8.517 & 0.76 \\
MAPE & - & - & - & - & 3.39 \\
\hline
\end{tabular}

$$
\mathrm{MAPE}=\frac{1}{m} \sum_{a=1}^{m} \frac{\left|\mathrm{OVMTT}_{a}-\mathrm{TTB}_{a}\right|}{\mathrm{OVMTT}_{a}},
$$

where $m$ denotes the total number of links, TTB denotes the estimated TTB on the link $a$, and OVMTT denotes the observed values of the mean travel time.

Table 5 shows the proposed model for TTB with different confidence levels to estimate the OVMTT. As for different links, OVMTT with different certain error is calculated based on the original data of floating car speeds, which is caused by the road level, the road length, and the topological structure of the road network. Therefore, a certain measurement error leads to relatively large errors on some links. We found that the MAPE is relatively small for several single links. However, several specific links may have relatively large estimation errors based on the proposed model of equation (17), assuming that the traveler makes a trip from node IDs 11333 to 11163 (or 11226). The resulting estimates are presented in Table 6 . The estimates indicate that the proposed model makes an effectively approximate estimate for the OVMTT, although a certain error exists between the OVMTT and ground-truth values of mean travel time. Figure 11 also displays the value of TTB under different travel time reliabilities based on the proposed model, which shows that travelers can select an appropriate departure time to make a trip based on their requirement of travel time reliability.

In this empirical example, the TTB is analyzed in a conventional traffic environment during the morning rush hour. Therefore, all links have not degenerated, and the CDC is equal to 1 for any link. In this case, we verified the validity of the proposed model of equation (17) to provide the TTB for travelers. However, the proposed model did not obtain the confirmation of the real example when the CDC of the link changed during a traffic accident. But the approach can be demonstrated in a simulated environment where the CDC of the link changes due to any incident. As mentioned in Section 5, the proposed model of equation (17) can estimate the TTB for travelers in the case of road capacity degradation based on the results of the example of optimal routing.

Therefore, extending the proposed model with considerably accurate data is also worth examining and the application to various realistic networks with empirical data is desirable. 
TABLE 6: Estimated travel time and OVMTT for route.

\begin{tabular}{ccccccc}
\hline \multicolumn{2}{c}{ Link no. } & OVMTT & \multicolumn{2}{c}{$\lambda=0$} & $\lambda=1.64$ & \multicolumn{2}{c}{$\lambda=3.89$} \\
From & To & $(\mathrm{s})$ & $\begin{array}{c}\text { TTB } \\
(\mathrm{s})\end{array}$ & $\begin{array}{c}\text { TTB } \\
(\mathrm{s})\end{array}$ & $\begin{array}{c}\text { TTB } \\
(\mathrm{s})\end{array}$ & $\begin{array}{c}\text { Error } \\
(\%)\end{array}$ \\
\hline 11333 & 11163 & 59.537 & 45.639 & 49.175 & 54.027 & 9.25 \\
11329 & 11226 & 58.475 & 45.255 & 48.841 & 53.765 & 8.05 \\
\multicolumn{2}{c}{ MAPE } & - & - & - & - & 8.65 \\
\hline
\end{tabular}

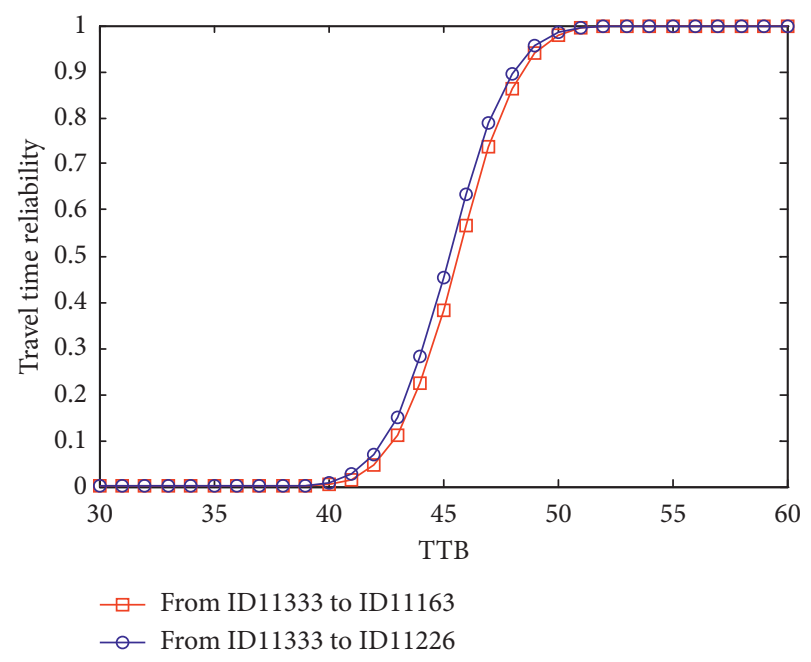

Figure 11: Value of TTB under different travel time reliabilities.

\section{Conclusions}

In this study, we introduced the CDC and DDFS to establish the travel time performance function based on the BPR function. We present the stochastic model to assess travel time reliability for travel route choice in the transportation network, which can evade the internal relation between traffic capacity and demand on the whole and investigate the effect of traffic capacity and demand for travel time variability.

Theoretically, the sensitivity of ETT and TTB model for the CDC of traffic capacity is different under different intervals of DDFS. This conclusion was verified through some case studies. The randomness analysis of demand and supply plays an important role in travel time variability. The CDC and DDFS have significant influence on the MAPE between the proposed TTB model and the ground-truth values of travel time. We used the simplified vehicle speed data of morning rush hour to derive an estimation method for road section saturation based on traffic flow theory. In conclusion, the DDFS is in accordance more with the generalized extreme value distribution compared with other distributions, such as normal, Johnson SB, and Weibull, through a simple case study with real-world data from the Western 3rd Ring-Road Expressway. The empirical analysis illustrates the effectiveness of the computational approach and the proposed models.

Our proposed TTB model is highly suitable for estimating travel time reliability of urban expressways or highway and even a relatively minor road network. These traffic scenarios can weaken the spatial-temporal correlation of road sections. Therefore, additional studies should be conducted based on the proposed TTB model. Extension of the TTB model to consider link correlation for each route that reduces the MAPE in degradation network would be interesting. We only conducted a case study on the road section from the Western 3rd Ring-Road Expressway to analyze our proposed model. A large-scale statistical should be included in future research. Empirical studies verify only roughly the effectiveness of the model. Therefore, we should provide a statistical analysis that reveals the distribution diagram of all links in a specific period by gathering accurate data regarding road section saturation. We can then provide a rational departure time and route choice based on the proposed model in traffic engineering, which is an important issue for future studies.

\section{Data Availability}

Floating car speed data used to support the findings of this study are available from the first author upon request.

\section{Conflicts of Interest}

The authors declare that there are no conflicts of interest regarding the publication of this paper.

\section{Acknowledgments}

This work was supported by the National Key R\&D Program of China (grant nos. 2017YFC0840200, 2018YFB1601104, and 2018YFC0807500) and Science and Technology Project of Beijing Municipal Commission of Science and Technology (grant no. Z181100003918011).

\section{References}

[1] Y. Asakura, "Comparison of some reliability models in a deteriorated road network," Journal of the Eastern Asia Society for Transportation Studies, vol. 2, pp. 705-720, 1997.

[2] Y. Asakura, E. Hato, and M. Kashiwadani, "Stochastic network design problem: an optimal link investment model for reliable network," in Network Reliability of Transport, Emerald Group Publishing Limited, Bingley, UK, 2003.

[3] M. G. H. Bell and Y. Lida, Transportation Network Analysis, John Wiley and Sons, Hoboken, NJ, USA, 2014.

[4] A. Chen, H. Yang, H. K. Lo, and W. H. Tang, "Capacity reliability of a road network: an assessment methodology and numerical results," Transportation Research Part B: Methodological, vol. 36, no. 3, pp. 225-252, 2002.

[5] H. K. Lo and Y. K. Tung, "A chance constrained network capacity model," in Reliability of Transport Networks, Research Studies Press Ltd, Hertfordshire, UK, 2000.

[6] M. Arezoumandi, "Estimation of travel time reliability for freeways using mean and standard deviation of travel time," Journal of Transportation Systems Engineering and Information Technology, vol. 11, no. 6, pp. 74-84, 2011.

[7] S. Clark and D. Watling, "Modelling network travel time reliability under stochastic demand," Transportation Research Part B: Methodological, vol. 39, no. 2, pp. 119-140, 2005.

[8] J. Y. T. Wang, M. Ehrgott, and A. Chen, "A bi-objective user equilibrium model of travel time reliability in a road 
network," Transportation Research Part B: Methodological, vol. 66, pp. 4-15, 2014.

[9] K. Uchida, "Estimating the value of travel time and of travel time reliability in road networks," Transportation Research Part B: Methodological, vol. 66, pp. 129-147, 2014.

[10] F. Lei, Y. Wang, G. Lu, and J. Sun, "A travel time reliability model of urban expressways with varying levels of service," Transportation Research Part C: Emerging Technologies, vol. 48, pp. 453-467, 2014.

[11] M. Ng and S. T. Waller, "A computationally efficient methodology to characterize travel time reliability using the fast Fourier transform," Transportation Research Part B: Methodological, vol. 44, no. 10, pp. 1202-1219, 2010.

[12] C. Chen, A. Skabardonis, and P. Varaiya, "Travel-time reliability as a measure of service," Transportation Research Record: Journal of the Transportation Research Board, vol. 1855, no. 1, pp. 74-79, 2003.

[13] A. König and K. W. Axhausen, "The reliability of the transportation system and its influence on the choice behavior," in Proceedings of the 2nd Swiss Transport Research Conference, pp. 20-22, Ascona, Switzerland, March 2002.

[14] H. Ortega, L. Chocano, C. Palma, and I. Samanez, Travel Time Reliability as an Emergent Property of Transportation Networks, Blackwell Publishing Ltd, Hoboken, NJ, USA, 2012.

[15] H. Shao, W. H. K. Lam, and Q. Meng, "Travel time reliabilitybased traffic assignment problem," Journal of Management Sciences in China, vol. 12, no. 5, pp. 27-35, 2009.

[16] H. Shao, W. H. K. Lam, and M. L. Tam, "A reliability-based stochastic traffic assignment model for network with multiple user classes under uncertainty in demand," Networks and Spatial Economics, vol. 6, no. 3-4, pp. 173-204, 2006.

[17] Z. Zhou and A. Chen, "Comparative analysis of three user equilibrium models under stochastic demand," Journal of Advanced Transportation, vol. 42, no. 3, pp. 239-263, 2008.

[18] Y. Asakura, "Reliability measures of an origin and destination pair in a deteriorated road network with variable flows," in Proceedings of the 4th European Operational Research Societies Transportation Meeting, Göteborg, Sweden, September 1998.

[19] H. K. Lo, X. W. Luo, and B. W. Y. Siu, "Degradable transport network: travel time budget of travelers with heterogeneous risk aversion," Transportation Research Part B: Methodological, vol. 40, no. 9, pp. 792-806, 2006.

[20] W. H. K. Lam, H. Shao, and A. Sumalee, "Modeling impacts of adverse weather conditions on a road network with uncertainties in demand and supply," Transportation Research Part B: Methodological, vol. 42, no. 10, pp. 890-910, 2008.

[21] H. Shao, Variational inequality models and solution algorithms for reliability-based traffic assignment problems, Nanjing University, Nanjing, China, Ph.D. dissertation, 2007.

[22] B. W. Y. Siu and H. K. Lo, "Doubly uncertain transportation network: degradable capacity and stochastic demand," European Journal of Operational Research, vol. 191, no. 1, pp. 166-181, 2008.

[23] Bureau of Public Roads, Traffic Assignment Manual, U.S. Dept. of Commerce, Ubran Planning Division, Washington, DC, USA, 1964.

[24] J. B. Zhou, H. Chen, X. W. Li, and L. Wang, "Research on model of road impedance function and applicability," Highway, vol. 7, no. 7, pp. 180-184, 2013.

[25] Y. Jiang, H.-J. Sun, and J.-J. Wu, "Comparative analysis of transportation network design problem under stochastic capacity," Journal of Transportation Systems Engineering and Information Technology, vol. 14, no. 3, pp. 85-90, 2014.
[26] H. K. Lo and Y.-K. Tung, "Network with degradable links: capacity analysis and design," Transportation Research Part B: Methodological, vol. 37, no. 4, pp. 345-363, 2003.

[27] Y. Nie, "Multi-class percentile user equilibrium with flowdependent stochasticity," Transportation Research Part B: Methodological, vol. 45, no. 10, pp. 1641-1659, 2011.

[28] Z. Tan, H. Yang, and R. Guo, "Pareto efficiency of reliabilitybased traffic equilibria and risk-taking behavior of travelers," Transportation Research Part B: Methodological, vol. 66, pp. 16-31, 2014.

[29] X. Xu, A. Chen, L. Cheng, and H. K. Lo, "Modeling distribution tail in network performance assessment: a mean-excess total travel time risk measure and analytical estimation method," Transportation Research Part B: Methodological, vol. 66, pp. 32-49, 2014.

[30] M. X. Li, "Analytical models for quantifying travel time variability based on stochastic capacity and demand distributions," in Proceedings of the Transportation Research Board 90th Annual Meeting, Washington, DC, USA, January 2011.

[31] L.-J. Tian, H.-J. Huang, and Z.-Y. Gao, "A cumulative perceived value-based dynamic user equilibrium model considering the travelers' risk evaluation on arrival time," Networks and Spatial Economics, vol. 12, no. 4, pp. 589-608, 2012.

[32] P. Cai, Y. Wang, G. Lu, P. Chen, C. Ding, and J. Sun, “A spatiotemporal correlative $\mathrm{k}$-nearest neighbor model for short-term traffic multistep forecasting," Transportation Research Part C: Emerging Technologies, vol. 62, pp. 21-34, 2016.

[33] N. Liu, S. C. Zhao, and N. He, "Further study of impedance function based on BPR function," Journal of Wuhan University of Technology (Transportation Science \& Engineering), vol. 37, pp. 545-548, 2013.

[34] V. Rotar, Probability Theory, World Scientific Publishing Co., Ltd, Singapore, 1997.

[35] Y. V. Prokhorov and V. Statulevicius, Limit Theorems of Probability Theory, Springer-Verlag, New York, NY, USA, 2000. 


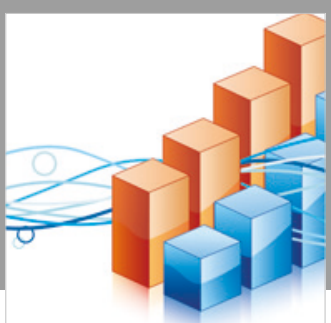

Advances in

Operations Research

\section{-n-m}
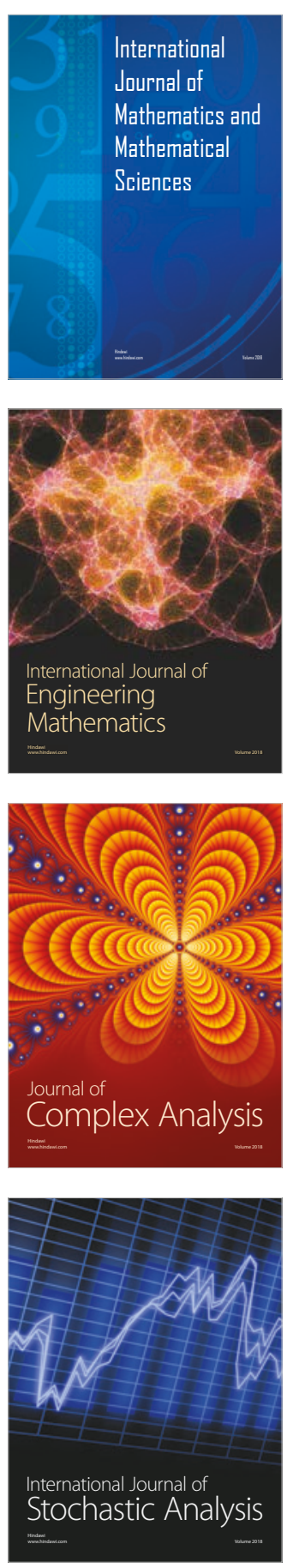
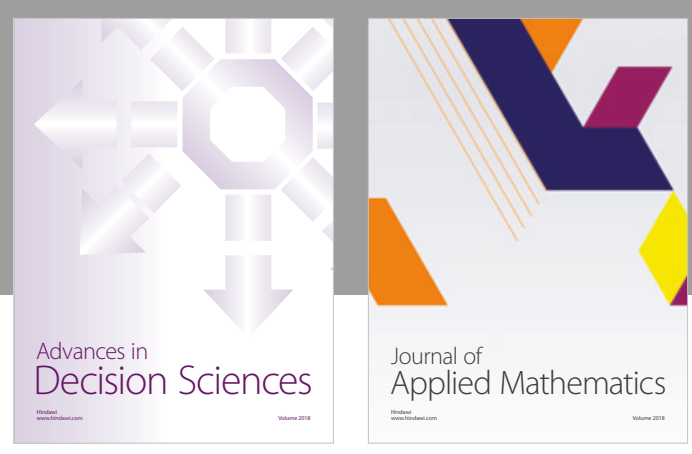

Journal of

Applied Mathematics
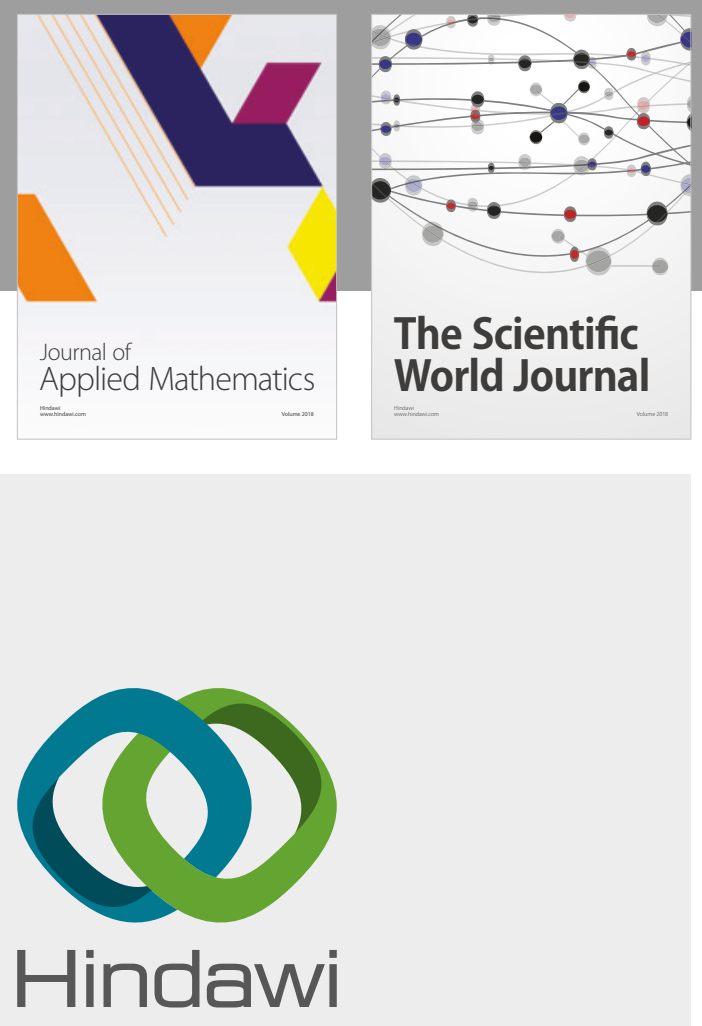

Submit your manuscripts at

www.hindawi.com

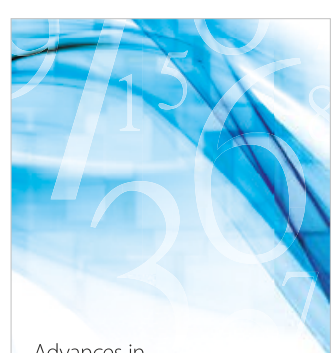

Advances in
Numerical Analysis
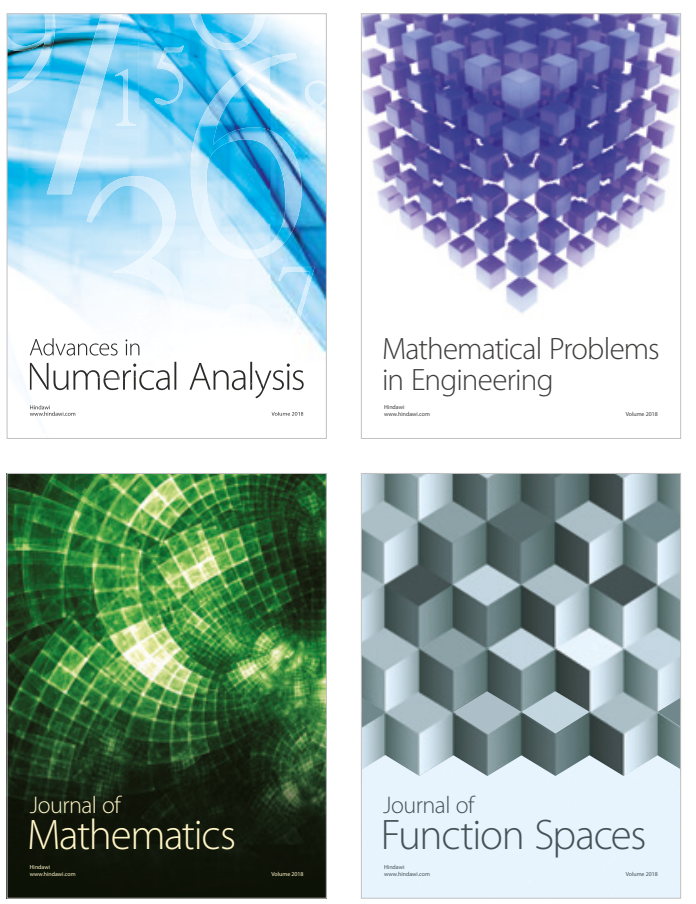

Mathematical Problems in Engineering

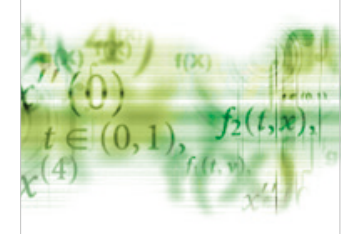

International Journal of

Differential Equations

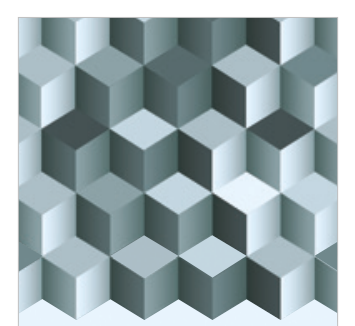

Journal of

Function Spaces
The Scientific

World Journal

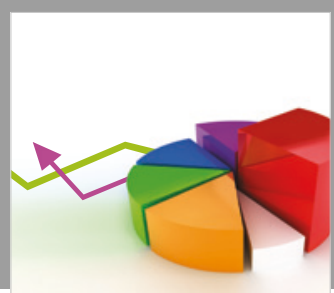

Journal of

Probability and Statistics
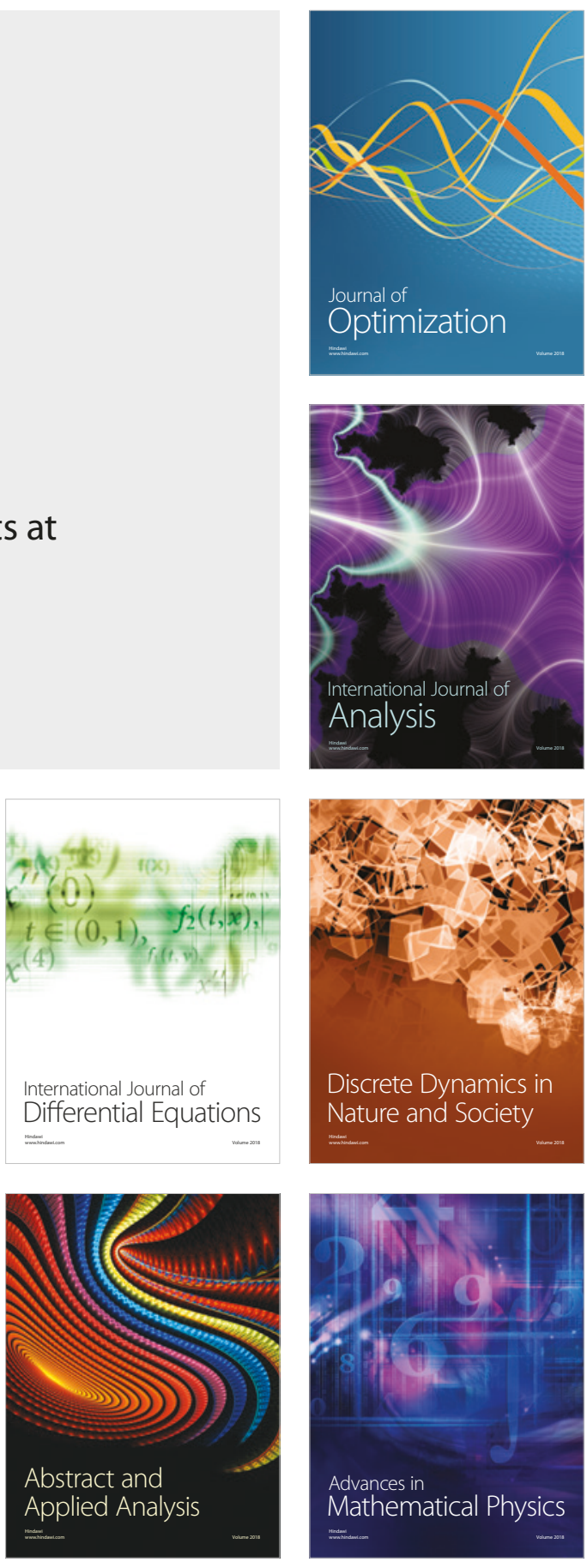